\title{
Cloud-Top Temperatures for Precipitating Winter Clouds
}

\author{
JAY W. HANNA \\ NOAA/NESDIS/Satellite Services Division, Camp Springs, Maryland \\ DAVID M. SCHULTZ* \\ Cooperative Institute for Mesoscale Meteorological Studies, University of Oklahoma, and NOAA/National Severe Storms Laboratory, \\ Norman, Oklahoma \\ ANTONIO R. IRVING \\ NOAA/NESDIS/Satellite Services Division, Camp Springs, Maryland
}

(Manuscript received 2 August 2006, in final form 2 March 2007)

\begin{abstract}
To explore the role of cloud microphysics in a large dataset of precipitating clouds, a 6-month dataset of satellite-derived cloud-top brightness temperatures from the longwave infrared band (channel 4) on the Geostationary Operational Environmental Satellite (GOES) is constructed over precipitation-reporting surface observation stations, producing 144738 observations of snow, rain, freezing rain, and sleet. The distributions of cloud-top brightness temperatures were constructed for each precipitation type, as well as light, moderate, and heavy snow and rain. The light-snow distribution has a maximum at $-16^{\circ} \mathrm{C}$, whereas the moderate- and heavy-snow distributions have a bimodal distribution with a primary maximum around $-16^{\circ}$ to $-23^{\circ} \mathrm{C}$ and a secondary maximum at $-35^{\circ}$ to $-45^{\circ} \mathrm{C}$. The light, moderate, and heavy rain, as well as the freezing rain and sleet, distributions are also bimodal with roughly the same temperature maxima, although the colder mode dominates when compared with the snow distributions. The colder of the bimodal peaks trends to lower temperatures with increasing rainfall intensity: $-45^{\circ} \mathrm{C}$ for light rain, $-47^{\circ} \mathrm{C}$ for moderate rain, and $-50^{\circ} \mathrm{C}$ for heavy rain. Like the distributions for snow, the colder peak increases in amplitude relative to the warmer peak at heavier rainfall intensities. The steep slope in the snow distribution for cloud-tops warmer than $-15^{\circ} \mathrm{C}$ is likely due to the combined effects of above-freezing cloud-top temperatures not producing snow, the activation of ice nuclei, the maximum growth rate for ice crystals at temperatures near $-15^{\circ} \mathrm{C}$, and ice multiplication processes from $-3^{\circ}$ to $-8^{\circ} \mathrm{C}$. In contrast, the rain distributions have a gentle slope toward higher cloud-top brightness temperatures $\left(-5^{\circ}\right.$ to $\left.0^{\circ} \mathrm{C}\right)$, likely due to the warm-rain process. Last, satellite-derived cloud-top brightness temperatures are compared with coincident radiosonde-derived cloud-top temperatures. Although most differences between these two are small, some are as large as $\pm 60^{\circ} \mathrm{C}$. The cause of these differences remains unclear, and several hypotheses are offered.
\end{abstract}

\section{Introduction}

The temperatures inside a cloud can be important in modulating the cloud microphysics to produce precipitation. For example, ice nucleates from the vapor phase

\footnotetext{
* Current affiliation: Division of Atmospheric Sciences, Department of Physical Sciences, University of Finland, and Finnish Meteorological Institute, Helsinki, Finland.
}

Corresponding author address: Jay Hanna, E/SP23, 5200 Auth Rd., Rm. 401, Camp Springs, MD 20746.

E-mail: jay.hanna@noaa.gov through the activation of ice nuclei below temperatures from approximately $-7^{\circ}$ to $-16^{\circ} \mathrm{C}$, depending on the composition of the ice nuclei (e.g., Rogers and Yau 1989, p. 154). Furthermore, strong vertical motion in the temperature regime of maximum dendritic ice crystal growth (from $-12^{\circ}$ to $-18^{\circ} \mathrm{C}$ ) is believed to be a factor in the production of heavy snowfall (e.g., Auer and White 1982).

Despite the quantitative temperature information inherent in satellite data, few studies have related the cloud-top brightness temperature to the observed precipitation type (e.g., snow, rain, freezing rain, and sleet). Instead, applications for forecasting snowfall in real time are limited to qualitative methods identifying 
regions of low cloud-top temperatures (e.g., Beckman 1987; Johnston 1995). In contrast, satellite-derived rainfall techniques have tried to find relationships between cloud-top brightness temperature and rainfall rates with varying levels of success (e.g., Scofield and Oliver 1977; Griffith et al. 1978; Scofield 1987; O'Sullivan et al. 1990; Vicente et al. 1998; Ba et al. 2003). In this note, we ask if there is a difference in the cloud-top brightness temperatures associated with different types of precipitation at the surface. Specifically, for a large sample of precipitation events, what can the distribution of cloud-top brightness temperature tell us about the physical processes acting inside precipitating clouds?

The purpose of this note is to explore a 6-month dataset of surface observations of precipitation and the associated satellite-derived cloud-top brightness temperatures. In section 2 , the data are described. In section 3 , distributions of cloud-top brightness temperatures for rain, snow, freezing rain, and sleet are presented. Satellite-derived cloud-top brightness temperatures and cloud-top temperatures derived from radiosonde data are compared in section 4, showing large unexplained discrepancies between the two methods. Section 5 concludes this paper.

\section{Data}

Six months of data were collected over two winters. For February-March 2003, cloud-top brightness temperatures from the longwave infrared band (channel 4; $10.2135-11.2045 \mu \mathrm{m})$ on the Geostationary Operational Environmental Satellite-8 (GOES-8) spacecraft were collected over all precipitating surface observing stations throughout the contiguous United States (CONUS). After GOES-12 became the operational satellite covering the eastern United States on 1 April 2003, cloud-top brightness temperatures from the longwave infrared band (channel 4; 10.2344-11.2397 $\mu \mathrm{m}$ ) on GOES-12 were collected for December 2003-March 2004. The change in instrumentation during the study period had a negligible impact on satellite-derived cloud-top brightness temperatures as intercalibration studies for similar wavelengths between GOES-8, GOES-12, and the higher-resolution polar-orbiting satellites were generally within $\pm 1.0 \mathrm{~K}$ (Gunshor et al. 2003). Cloud-top brightness temperature was constructed by taking the mean brightness temperature of a $2 \times 2$ pixel box $\left(\sim 36.8 \mathrm{~km}^{2}\right.$ at nadir) centered over the surface observing station to minimize navigational and parallax errors of the satellite data and to account for any horizontal advection of the hydrometeors (Schmit et al. 2001). This mean cloud-top brightness temperature was included in the dataset if the standard deviation of all the pixels sampled was less than or equal to $1.0 \mathrm{~K}$ to ensure horizontal homogeneity in the cloud height. The coverage time of the satellite scan was chosen to best correspond with the standard hourly surface reports, which are generally reported approximately $10 \mathrm{~min}$ before the top of the hour. This fact implies that the time difference between the surface precipitation observation and the satellite scan should rarely be more than $10 \mathrm{~min}$.

The method of obtaining cloud-top brightness temperature outlined above, as well as our subsequent interpretation of those cloud-top temperatures, makes three critical assumptions: 1) the cloud that produced the hydrometeor behaves as a blackbody, 2) the remotely sensed cloud-top brightness temperature is the cloud that produced the hydrometeors, and 3) the cloud-top brightness temperature is the lowest temperature in the cloud. The validity of these assumptions is explored in section 4 .

\section{Cloud-top brightness temperatures by precipitation type}

Based on the criteria in section 2, a total of 145062 observations of mean cloud-top brightness temperatures associated with surface precipitation observations were obtained. In this study, four types of surface precipitation types were considered: rain, snow, freezing rain, and sleet. Mixtures of precipitation types and snow grains were eliminated, leaving 144738 observations. Surface precipitation types were also categorized by intensity (light, moderate, and heavy), with intensity thresholds determined by the precipitation-sensing algorithm on the Automated Surface Observing System (ASOS) and the Automated Weather Observing System (AWOS). The distributions of mean cloud-top brightness temperature are discussed in section 3a, whereas the implications for these distributions in terms of cloud microphysics and dynamics, as well as a comparison with the previous literature, are discussed in sections $3 b-d$.

\section{a. Distributions}

A total of 93616 snow observations were collected, of which 89828 (95.96\%) were light, 3353 (3.58\%) were moderate, and $433(0.46 \%)$ were heavy. The distribution of cloud-top brightness temperatures for clouds producing snow is displayed in Fig. 1. Because the overwhelming majority of snow reports are light snow, the distribution for all snow observations (Fig. 1a) is nearly identical to that for light snow (Fig. 1b). The mode for 

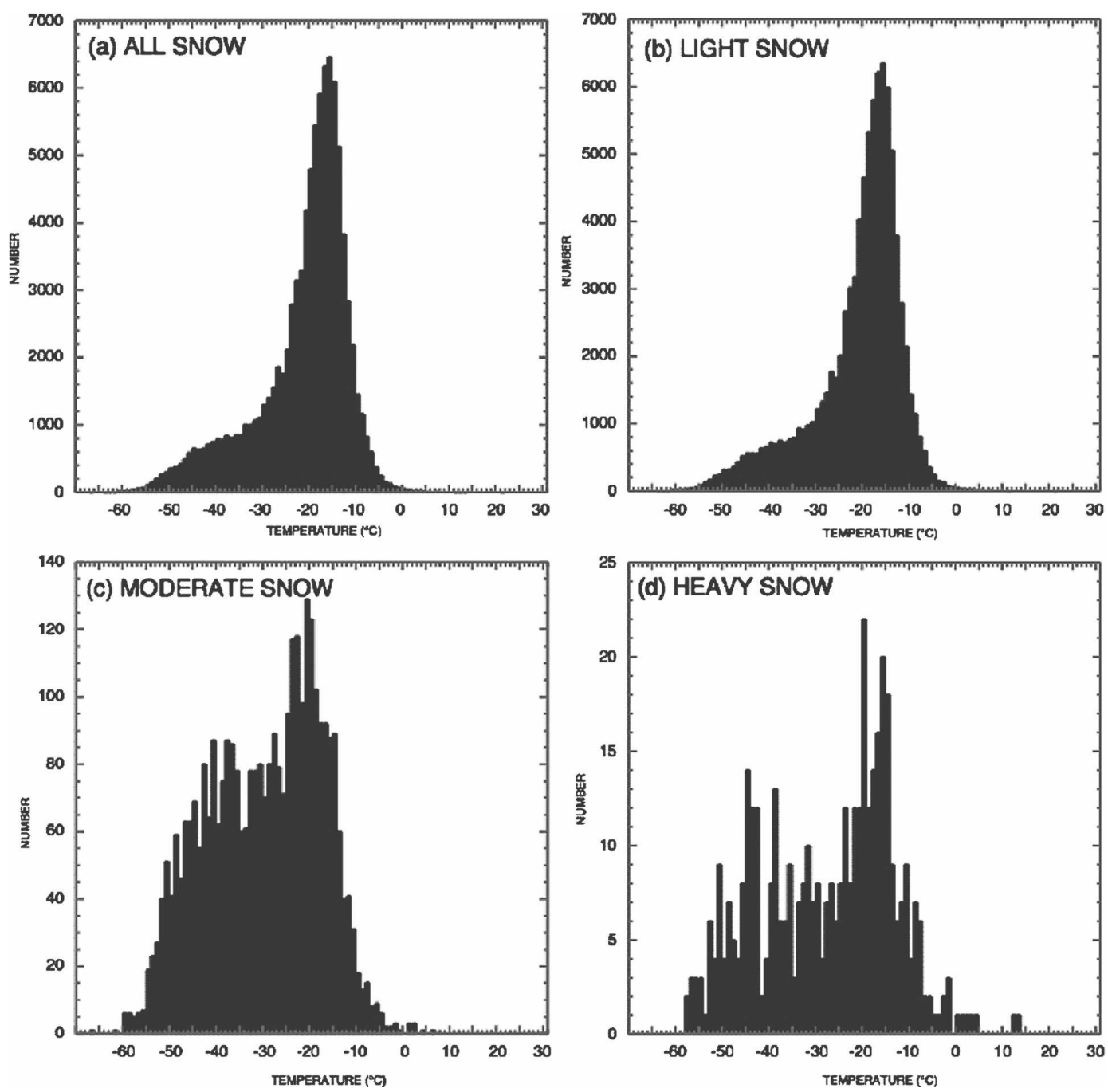

FIG. 1. Histograms of cloud-top brightness temperatures $\left({ }^{\circ} \mathrm{C}\right)$ for (a) all snow, (b) light snow, (c) moderate snow, and (d) heavy snow.

light snow occurs at $-16^{\circ} \mathrm{C}$, and the distribution is heavily skewed toward lower temperatures (Fig. 1b). A sharp drop in the distribution occurs toward higher temperatures, especially over the range from $-15^{\circ} \mathrm{C}$ to $-10^{\circ} \mathrm{C}$. Nevertheless, a small percentage $(4.13 \%)$ of cloud-top brightness temperatures with light snow occurs greater than $-10^{\circ} \mathrm{C}$. In contrast, the distributions for moderate and heavy snow are both bimodal with comparatively broad peaks from $-16^{\circ}$ to $-23^{\circ} \mathrm{C}$ and from $-35^{\circ}$ to $-45^{\circ} \mathrm{C}$ (Figs. 1c,d).

There were fewer rain observations (49 809) than snow observations because the months we chose occurred in the cool season. A total of 42469 observations $(85.3 \%)$ were light rain, $6731(13.5 \%)$ were moderate, and $609(1.2 \%)$ were heavy. The distribution of cloudtop brightness temperatures for clouds producing rain is displayed in Fig. 2. As with that for snow (Figs. 1a,b), the distribution for all-rain observations is dominated by the large percentage of light-rain events (cf. Figs. $2 a, b)$. The distributions for various intensities of rain, however, differ from those of snow in three significant ways. First, rather than a single mode in cloud-top brightness temperature for light snow at $-16^{\circ} \mathrm{C}$ (Fig. 1b), light rain possesses a bimodal distribution with a dominant peak around $-45^{\circ} \mathrm{C}$ and a secondary peak around $-14^{\circ} \mathrm{C}$ (Fig. 2b). Second, the light-rain distribution has a gentler slope toward higher cloud-top brightness temperatures (from $-5^{\circ}$ to $0^{\circ} \mathrm{C}$ ) than the steeper slope for light snow at temperatures higher than $-15^{\circ} \mathrm{C}$ (cf. Figs. $2 \mathrm{~b}$ and $1 \mathrm{~b}$ ). Third, the colder of the bimodal peaks trends to lower temperatures with increasing rainfall intensity. Specifically, the mode is 

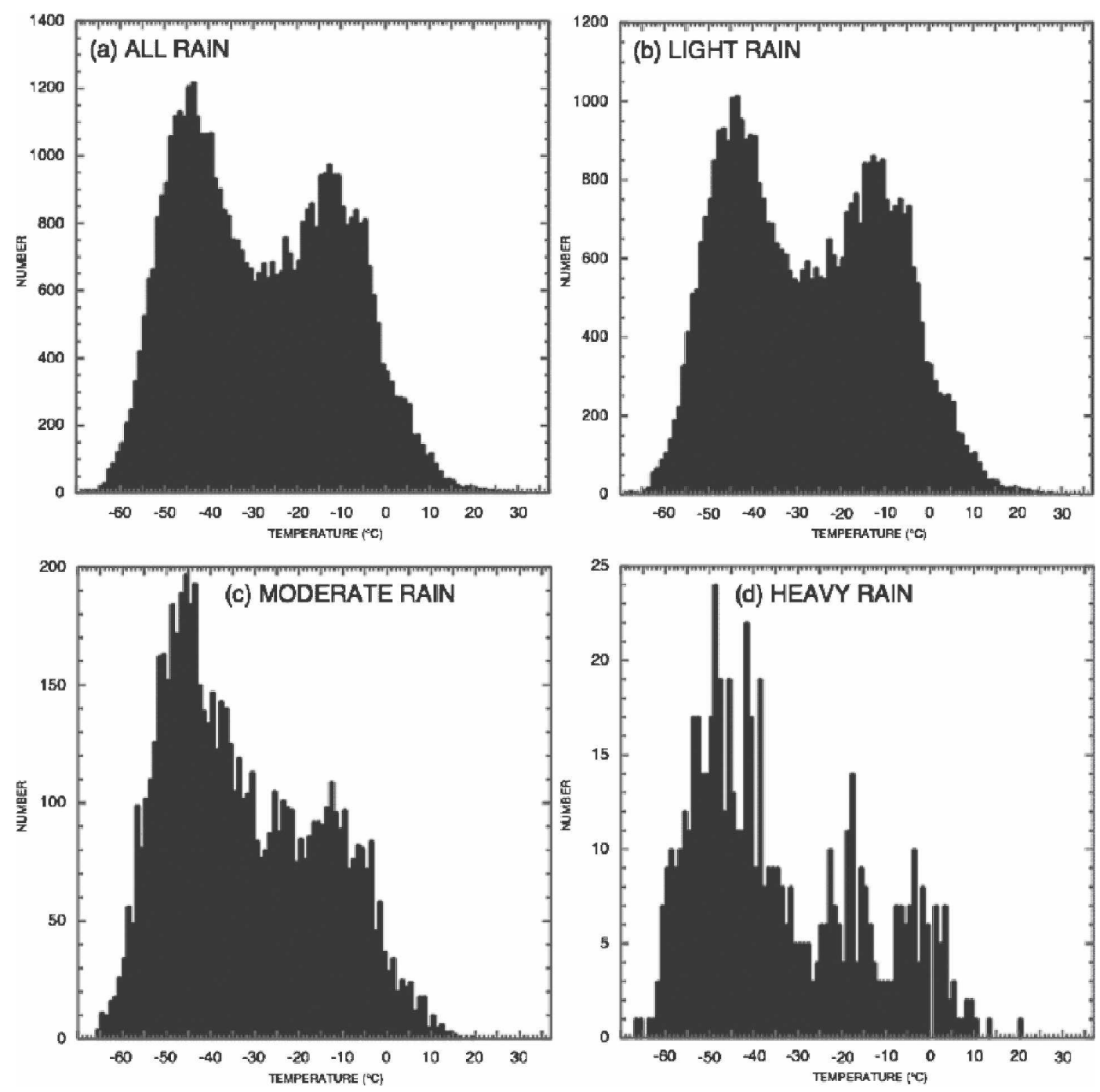

FIG. 2. As in Fig. 1, but for rain.

$-45^{\circ} \mathrm{C}$ for light rain (Fig. $\left.2 \mathrm{~b}\right),-47^{\circ} \mathrm{C}$ for moderate rain (Fig. 2c), and $-50^{\circ} \mathrm{C}$ for heavy rain (Fig. 2d). Like the distributions for snow, the colder bimodal peak has greater amplitude at heavier rainfall intensities relative to the warmer peak (cf. Figs. 1 and 2).

Last, distributions of cloud-top brightness temperatures for freezing rain and sleet are shown in Fig. 3. There are fewer observations of freezing rain and sleet (1163 and 150, respectively) than rain and snow, so the distributions are not broken up by intensity. Generally, these observations are similar to those for rain (cf. Figs. 3 and 2a), albeit more noisy. There is some indication that the warmer mode in the freezing-rain distribution $\left(-8^{\circ} \mathrm{C}\right.$ in Fig. 3a) is warmer and broader than in the rain case $\left(-14^{\circ} \mathrm{C}\right.$ in Fig. 2a), although the small sample size of the freezing-rain events may be an issue. The distribution of sleet (Fig. 3b) is not inconsistent with the freezing-rain distribution; with a significantly lower sample size for sleet, however, a more detailed comparison is difficult.

The shapes of the distributions in Figs. 1-3 raise several important questions that require explanation. These questions are discussed in sections $3 \mathrm{~b}-3 \mathrm{~d}$.

\section{b. Why does the light-snow distribution have one mode, whereas the other distributions (i.e., moderate and heavy snow, rain, freezing rain, sleet) have two modes?}

The shapes of these distributions, at least for rain clouds, have been demonstrated previously. For example, Weickmann (1957, his Fig. 13) summarized previously published distributions of cloud-top temperatures derived from aircraft soundings for various types 

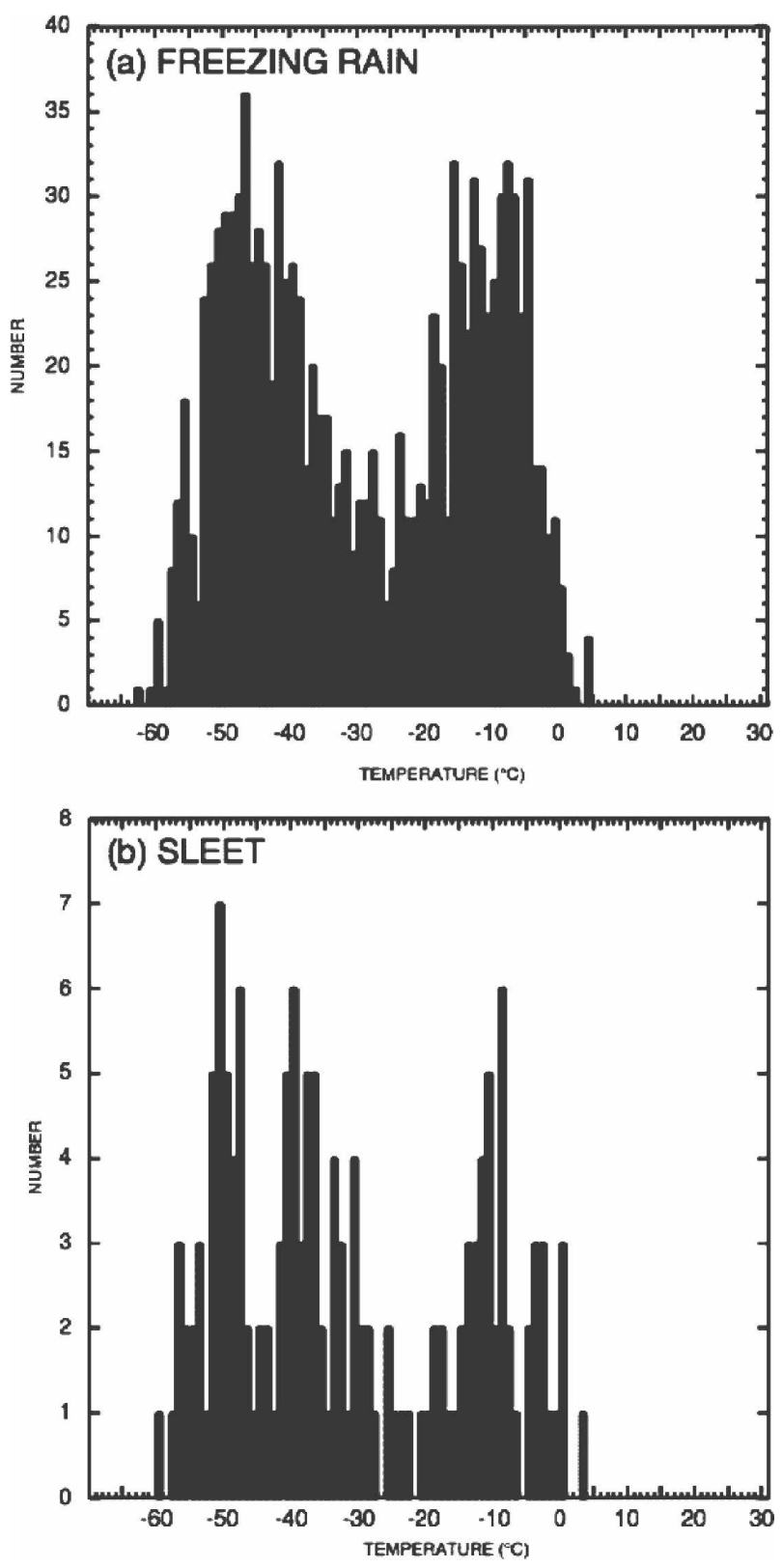

FIG. 3. Histograms of cloud-top brightness temperatures $\left({ }^{\circ} \mathrm{C}\right)$ for (a) freezing rain and (b) sleet.

of clouds, showing similar distributions to ours. The minimum temperature on Weickmann's graph, however, was only $-32^{\circ} \mathrm{C}$, so he was unable to see the colder mode, although Mason and Howorth's (1952) data on Weickmann's Fig. 13 may be depicting the edge of the colder mode. Ba et al. (2003) found bimodal distributions of cloud-top brightness temperature for rainfall of various intensities, and they found that the amplitude of the warmer peak decreased relative to the amplitude of the colder peak as the rain rate increased, consistent with our results (cf. Figs. 2b-d).
The two modes in nearly all the distributions illustrate two effects. The warmer mode around $-15^{\circ} \mathrm{C}$ occurs in a temperature regime favored for maximum dendritic growth of ice crystals (e.g., Rogers and Yau 1989, 158-163; Fukuta and Takahashi 1999). At this temperature regime, the Bergeron process is very effective, and rapid growth of dendritic ice occurs. Thus, clouds reaching temperatures at least this low are favored for the initiation of precipitation processes. Many of these clouds may reach the top of the planetary boundary layer, but a climatology of the cloud tops with respect to the boundary layer depth has not been performed.

The colder mode from approximately $-35^{\circ}$ to $-45^{\circ} \mathrm{C}$ generally represents the equilibrium levels for moist ascending air (whether unstable or stable), which tends to occur near the tropopause. Thus, the single mode of the light-snow distribution likely occurs because light snow tends to form in situations with greater stability (implying that deep, moist convection is not present or is not tropospheric deep), reducing the magnitude of the colder mode. The relative frequency of light snow tends to increase with warmer cloud tops (cf. Figs. 1bd), in contrast to moderate and heavy snow where the relative frequency increase with colder clouds top, which may imply deeper ascent and possibly greater instability.

\section{c. Why do the snow distributions have a steep decline from the warmer mode to higher temperatures over the range from $-15^{\circ}$ to $-8^{\circ} \mathrm{C}$ ?}

Previous research on the distribution of cloud-top temperatures in clouds solely producing snow has not been published to our knowledge. This was one of the reasons that motivated us to perform this study. One small dataset was published by Schultz et al. (2002, their Fig. 1), showing cloud-top temperatures derived from radiosonde data for only 64 snowfall events - no events had cloud tops warmer than $-5^{\circ} \mathrm{C}$.

The steep decline in the snow distributions is likely associated with four effects. First is that cloud-top temperatures higher than $0^{\circ} \mathrm{C}$ are not likely to produce frozen precipitation, so the steep decline to higher cloud-top temperatures for snow will be greater than that for rain (cf. Figs. 2a and 1a). Second is the maximum in dendritic ice-crystal growth occurring at about $-15^{\circ} \mathrm{C}$, as previously discussed. Third is the activation of ice nuclei. Ice nuclei present in the atmosphere do not begin nucleating ice until their temperature drops below a certain level, which is dependent on the structure of the ice nuclei. For many mineral substances in the atmosphere that act as ice nuclei, this temperature lies 
between $-7^{\circ}$ and $-16^{\circ} \mathrm{C}$ (e.g., Rogers and Yau 1989, p. 154). Fourth is the ice multiplication mechanism (e.g., Hallett and Mossop 1974; Mossop 1985). This mechanism occurs from $-3^{\circ}$ to $-8^{\circ} \mathrm{C}$, creating abundant ice splinters to increase the likelihood of ice and snow formation in the cloud. Thus, this sharp decline at temperatures higher than $-15^{\circ} \mathrm{C}$ (Fig. 1) is likely due to the above-freezing cloud tops, the loss of the dendriticgrowth process for precipitation production, the decrease in active ice nuclei, and ice multiplication processes. Although a steep decline exists, there tends to be no sharp upper bound for precipitation production (i.e., snow can occur with cloud tops as warm as $-1{ }^{\circ} \mathrm{C}$ ), indicating issues with our methodology (explored in section 4), data quality, or extremely active ice nuclei at high temperatures.

\section{d. In comparison with the snow distributions, why do the rain distributions have a less steep decline over the range from $-5^{\circ}$ to $0^{\circ} \mathrm{C}$ ?}

Comparing previous research with the present research is difficult because most previous studies did not separate clouds producing rain from those producing snow. For example, Peppler's (1940) climatology of cloud-top temperatures showed a similar sharp decrease in the frequency of cloud-top temperatures greater than $-12^{\circ} \mathrm{C}$ for precipitating clouds. Braham et al. (1951) found that radar echoes in New Mexico cumulus never developed for summit-level temperatures greater than $-12^{\circ} \mathrm{C}$. Mason and Howorth (1952) found that the frequency of rain/snow decreased dramatically for cloud-top temperatures greater than $-12^{\circ} \mathrm{C}$. Plank et al. (1955) found that when echo-top temperatures from a cloud radar reached between $-10^{\circ}$ and $-20^{\circ} \mathrm{C}$, onset of precipitation became likely. Weickmann's (1957, his Fig. 13) cases of supercooled water clouds, however, showed a peak around $-4^{\circ} \mathrm{C}$, indicating that ice nuclei had not been activated because the temperatures were not low enough.

That the rain distribution extends out to warmer cloud tops than that of snow (cf. Figs. 1a and 2a) is easily explained. Specifically, cloud-top brightness temperatures above $0^{\circ} \mathrm{C}$ with rain are not uncommon ( $5.1 \%$ of the total rain reports in Fig. 2a). Such warm clouds indicate that the formation of cloud ice is unlikely and warm-rain processes through the collisioncoalescence mechanism are likely occurring. Thus, the less steep declines in the distributions of rain are likely due to the warm-rain precipitation processes.

Thus, these distributions of the cloud-top brightness temperatures associated with various types of precipitating clouds in Figs. 1-3 imply microphysical differ- ences. In the next section, the cloud-top brightness temperatures derived from satellite are compared with upper-air profiles from radiosondes in an attempt to explore these processes further.

\section{Comparison between satellite-derived and radiosonde-derived cloud-top temperatures}

To test the accuracy of the satellite-derived cloud-top brightness temperatures and the assumptions listed in section 2, a subset of the 145062 observations of surface precipitation type was constructed where radiosonde profiles were coincident with a surface observing station reporting precipitation at 1100 or 2300 UTC (the approximate sounding release times). This subset numbered 345 observations. Cloud-top temperatures were determined from the radiosonde data using the method outlined in Wang and Rossow (1995).

Specifically, the Wang and Rossow (1995) method employs a vertical top-down examination of relative humidity with respect to water $\left(\mathrm{RH}_{w}\right)$ for temperatures above $273.16 \mathrm{~K}$ and with respect to ice $\left(\mathrm{RH}_{i}\right)$ for temperatures below $273.16 \mathrm{~K}$. Moist layers suggestive of possible clouds are indicated by levels where $\mathrm{RH}_{w}$ or $\mathrm{RH}_{\mathrm{i}}$ satisfies one of the following two criteria: 1) $\mathrm{RH}_{w}$ or $\mathrm{RH}_{i} \geq 87 \%$, or 2 ) $\mathrm{RH}_{w}$ or $\mathrm{RH}_{i} \geq 84 \%$ but $<87 \%$, and there is a $3 \%$ increase of the $\mathrm{RH}_{w}$ or $\mathrm{RH}_{i}$ from the higher level. The top-down examination of $\mathrm{RH}_{w}$ or $\mathrm{RH}_{i}$ continues until the level where $\mathrm{RH}_{w}$ or $\mathrm{RH}_{i}$ fails to meet the above criteria-this level is then determined to be the base of the moist layer. The moist layer is judged to be a cloud layer if the maximum $\mathrm{RH}_{w}$ or $\mathrm{RH}_{i}$ of the layer surpasses $87 \%$.

If a single moist layer existed, the cloud-top temperature was assigned the mean temperature of the top of the single moist layer and the layer immediately above. Five of the 345 soundings had no cloud-top temperature by the Wang and Rossow (1995) method. Additional moist layers that existed below the uppermost layer were also examined using the top-down approach to determine the frequency of multicloud layers. All radiosonde profiles were then examined to determine the frequency when cloud-top temperatures were not the lowest temperature in the cloud. The validity of the assumptions listed in section 2 is examined below.

\section{a. The cloud that produced the hydrometeor behaves as a blackbody}

In the GOES channel-4 wavelength, clouds absorb nearly all incident infrared radiation, acting nearly as a blackbody with emissivity approaching 1 (e.g., Kidder 


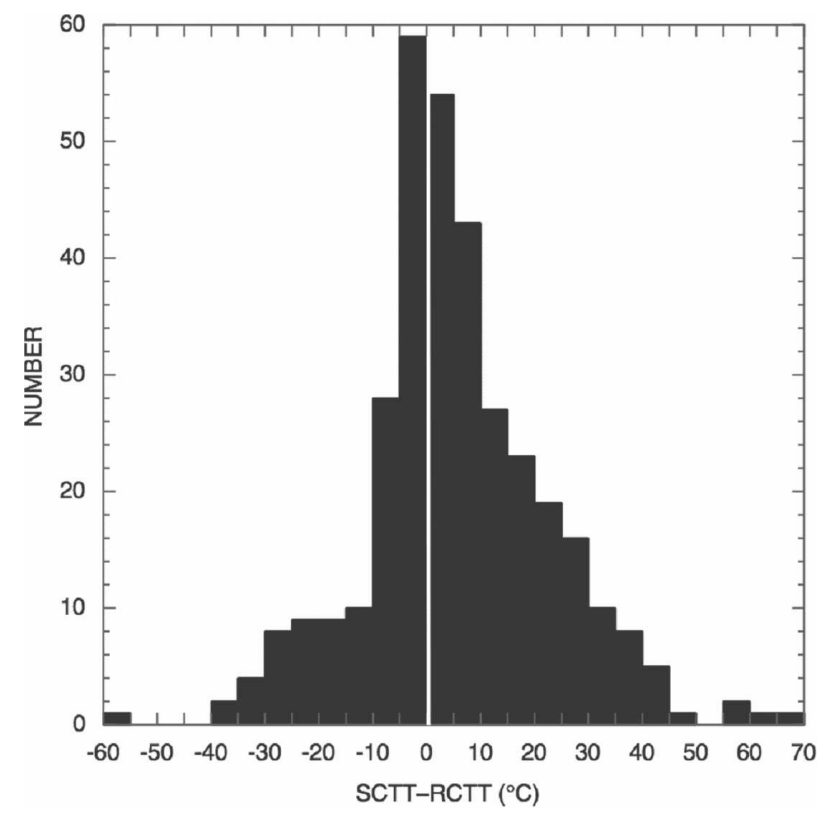

FIG. 4. Histogram of satellite-derived cloud-top brightness temperatures SCTT minus radiosonde-derived cloud-top temperatures RCTT $\left({ }^{\circ} \mathrm{C}\right)$. The vertical white line represents $0^{\circ} \mathrm{C}$ value for SCTT-RCTT.

and Vonder Haar 1995, p. 79). If clouds are nearly blackbodies, cloud-top temperatures can be inferred by converting emitted radiation to a brightness temperature. As a quality-control check using our data, satellite-derived cloud-top brightness temperatures composing the 340 precipitating surface reports collocated with radiosonde sites were compared with cloud-top temperatures using the Wang and Rossow (1995) method. The distribution of the difference between the satellitederived cloud-top brightness temperatures (SCTT), and radiosonde-derived cloud-top temperatures (RCTT) is plotted in Fig. 4. The values of SCTT RCTT are most commonly between $-5^{\circ}$ and $10^{\circ} \mathrm{C}$, but the broad distribution, including some values as large as $\pm 60^{\circ} \mathrm{C}$, suggests some major discrepancies with this comparison. Such discrepancies are similar to those previously published (e.g., Landolt et al. 2004; Sherwood et al. 2004; Holland et al. 2006), but much larger than the mean $1933 \mathrm{ft}(589 \mathrm{~m})$ published by Borneman (1978).

The differences between SCTT and RCTT can partially be explained by the temporal difference between the satellite scan and sounding-release times, which can be as much as $30 \mathrm{~min}$. Discrepancies can also result because of the horizontal drift of the radiosonde out of the $2 \times 2$ pixel box surrounding the surface station used to determine the cloud-top brightness temperature. In addition, discrepancies can be attributed to uncertain-

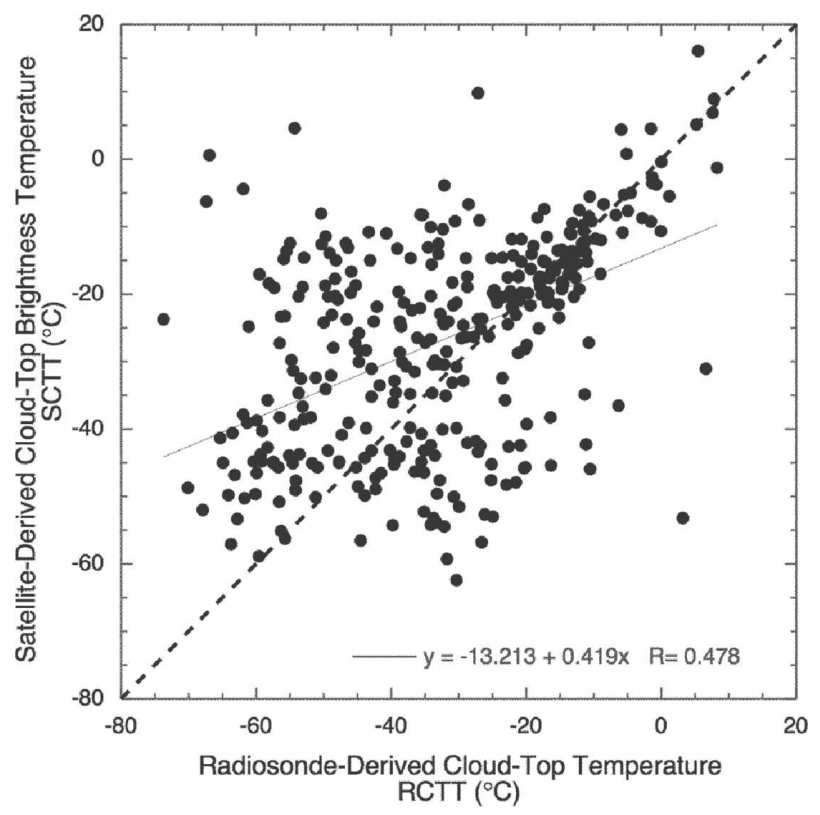

FIG. 5. Scatterplot of RCTT $\left({ }^{\circ} \mathrm{C}\right)$ vs SCTT $\left({ }^{\circ} \mathrm{C}\right)$. The dashed line represents the line of perfect fit, and the solid gray line represents a linear fit to the data.

ties in radiosonde humidity measurements (e.g., Miloshevich et al. 2001), inherent biases of the Wang and Rossow (1995) method overestimating cloud-top pressures (e.g., Holland et al. 2006), and the underestimation of deep convective clouds by GOES channel-4 brightness temperatures (e.g., Sherwood et al. 2004).

Many of the greatest and most numerous discrepancies, however, appear to be a result of moisture layers detected at very high altitudes by RCTT not detected by SCTT skewing the distribution to the right (Fig. 4). We believe this is a direct result of optically thin cirrus that goes undetected because of the 4-km resolution of GOES channel-4 data (e.g., Dessler and Yang 2003). In addition to the resolution constraints of the GOES-8 and GOES-12 data, unfortunately, the wavelength range of channel-4 data (approximately 10.2-11.2 $\mu \mathrm{m}$ ) is not the ideal wavelength to detect cirrus with thin optical depths (e.g., Dessler and Yang 2003). Thus, the frequency of optically thin cirrus may be greater than expected. Specifically, during two 3-day periods from December 2000 and June 2001, Dessler and Yang (2003) found that about one-third of cloud-free pixels identified by the Moderate Resolution Imaging Spectrometer (MODIS) on board the Terra satellite contained detectible thin cirrus as determined by the lidar at Nauru Island.

To gain a better understanding of these discrepancies, a scatterplot of RCTT versus SCTT was constructed (Fig. 5). The least discrepancies between the 
two methods occurred with warmer cloud tops, with the greatest clustering around $-20^{\circ}$ and $-10^{\circ} \mathrm{C}$ (Fig. 5). Both accuracy and precision between SCTT and RCTT decrease with decreasing cloud-top temperature, with SCTT being lower than RCTT at lower temperatures. These results of decreasing accuracy and precision for lower SCTT and RCTT agree with results from Landolt et al. (2004) and Holland et al. (2006). We believe that this is further evidence of optically thin cirrus providing occasionally large differences between SCTT and RCTT. Thus, although optically thin cirrus may explain some of the discrepancies for cold cloud tops in Fig. 5, the large spread at all temperatures suggests that the complete answer likely includes a variety of different explanations (e.g., Sherwood et al. 2004).

\section{b. The remotely sensed cloud-top brightness temperature is the cloud that produced the hydrometeor}

To address the question of whether or not the SCTT is the cloud that produced the hydrometeor, the 345 radiosondes that were collocated with precipitationreporting surface stations were examined to determine the frequency of multicloud layers using the Wang and Rossow (1995) method. Of the 345 radiosondes that were collocated with precipitation reporting surface stations, 137 (39.6\%) were clearly multicloud layer cases. In a study of 30 ocean sites, Wang and Rossow (1995) indicated that multilayered clouds occur approximately $56 \%$ of the time, more than the $39.6 \%$ frequency for multilayered clouds in our case over land. Wang and Rossow (1995, their Fig. 19) note a negligible seasonal dependence in the midlatitudes so the differences between our two studies is possibly geographically dependent. Because many of the multilayered clouds were cases of optically thin cirrus composed of small ice crystals and may be separated from lowerlevel clouds by some distance (i.e., implying large fall distances over which small ice crystals would likely sublimate), their ability to seed lower clouds and be involved in the microphysical processes producing precipitation is likely to be negligible (e.g., Pruppacher and Klett 1997, p. 559).

\section{c. The cloud-top temperature is the lowest temperature in the cloud}

To make microphysical inferences from satellitederived cloud-top brightness temperatures, it is necessary for the cloud-top temperature to be the lowest in the cloud. To address this question, the 340 radiosonde profiles were examined for cases where RCTT was not the lowest in the cloud. Of the 340 profiles, only 45
(13.2\%) were clearly cases where RCTT was not the lowest in the cloud. Cases where RCTT was not the lowest in the cloud were primarily due to optically thin cirrus near the tropopause and cases with cloud tops near the top of a frontal inversion. Thus, the cloud-top temperature is generally the lowest in the cloud.

\section{Conclusions}

The operational meteorological community is increasingly realizing the important role of cloud microphysics in the production of heavy precipitation, especially snow (e.g., Roebber et al. 2003). The goal of this note was to relate satellite-derived cloud-top brightness temperatures to coincident observations of precipitation at the surface and radiosonde profiles, and, in doing so, provide some insight into the microphysical processes inside the clouds. The distributions of cloud-top brightness temperatures from GOES satellite imagery over precipitating clouds show the following signatures.

- The distribution for light snow features one mode at $-16^{\circ} \mathrm{C}$, whereas all the other precipitation types (moderate and heavy snow, rain, freezing rain, and sleet) feature two modes around $-16^{\circ} \mathrm{C}$ and from $-35^{\circ}$ to $-50^{\circ} \mathrm{C}$. These two maxima likely indicate the temperature regimes of maximum ice crystal growth and the equilibrium level near the tropopause for moist ascending parcels, respectively.

- The distributions for snow are characterized by a steep decline at temperatures higher than $-15^{\circ} \mathrm{C}$, likely indicative of four processes: above-freezing cloud-top temperatures, nonactivation of ice nuclei, the decline in the growth rate of ice crystals at the higher temperatures, and ice multiplication processes. In contrast, because of the warm-rain process, the distributions for rain are characterized by a comparatively more gentle decline from $-5^{\circ}$ to $0^{\circ} \mathrm{C}$.

- Radiosonde-derived cloud-top temperatures are generally the lowest temperatures in the cloud with only $13.2 \%$ of soundings having the lowest temperature within the cloud rather than at the top of the cloud.

- A comparison between satellite-derived cloud-top brightness temperatures and corresponding radiosonde-derived cloud-top temperatures using a method by Wang and Rossow (1995) generally showed small differences (from $-5^{\circ}$ to $10^{\circ} \mathrm{C}$ ), although some errors were as large as $\pm 60^{\circ} \mathrm{C}$. Differences are largest for the coldest cloud tops. Differences of such large magnitude have been discussed previously (e.g., Landolt et al. 2004; Sherwood et al. 2004; Holland et al. 2006), and several hypotheses have been suggested, including optically thin cirrus. 
To date, no resolution has yet been found to this discrepancy (S. Sherwood 2006, personal communication).

Acknowledgments. Thanks are given to Tim Garrett, Dan Petersen, Steve Sherwood, and two anonymous reviewers for providing comments that improved this manuscript. Thanks are also given to Mark Ruminski for aiding in the cloud-top temperature retrieval algorithm, along with providing many helpful comments that improved the manuscript, and to Kevin Berberich for help with the large amount of data analysis. Funding for Schultz was provided by the NOAA/Office of Oceanic and Atmospheric Research under NOAAUniversity of Oklahoma Cooperative Agreement NA17RJ1227, U.S. Department of Commerce.

\section{REFERENCES}

Auer, A. H., and J. M. White, 1982: The combined role of kinematics, thermodynamics, and cloud physics associated with heavy snowfall episodes. J. Meteor. Soc. Japan, 60, 500-507.

Ba, M. B., A. Gruber, and M.-J. Jeong, 2003: Frequency distribution of rain rate with cloud top brightness temperature, and near-real time calibration of GOES multispectral rainfall algorithm. Preprints, 12th Conf. on Satellite Meteorology and Oceanography, Long Beach, CA, Amer. Meteor. Soc., P4.17.

Beckman, S. K., 1987: Use of enhanced IR/visible satellite imagery to determine heavy snow areas. Mon. Wea. Rev., 115, 2060-2087.

Borneman, R., 1978: Verification of satellite derived cloud tops. Natl. Wea. Dig., 3 (2), 5-9.

Braham, R. R., S. E. Reynolds, and J. H. Jarrell Jr., 1951: Possibilities for cloud seeding as determined by a study of cloud height versus precipitation. J. Meteor., 8, 416-418.

Dessler, A. E., and P. Yang, 2003: The distribution of tropical thin cirrus clouds inferred from Terra MODIS data. J. Climate, 16, 1241-1247.

Fukuta, N., and T. Takahashi, 1999: The growth of atmospheric ice crystals: A summary of findings in vertical supercooled cloud tunnel studies. J. Atmos. Sci., 56, 1963-1979.

Griffith, C. G., W. L. Woodley, P. G. Grube, D. W. Martin, J. Stout, and D. N. Sikdar, 1978: Rain estimation from geosynchronous satellite imagery-Visible and infrared studies. Mon. Wea. Rev., 106, 1153-1171.

Gunshor, M. M., T. J. Schmit, and W. P. Menzel, 2003: New analysis with the intercalibration of geostationary and polarorbiting radiances. Report of the 31st Meeting of the Coordination Group for Meteorological Satellites (CGMS XXXI), Ascona, Switzerland, European Organization for the Exploitation of Meteorological Satellites (EUMETSAT), 29 pp.

Hallett, J., and S. C. Mossop, 1974: Production of secondary ice particles during the riming process. Nature, 249, 26-28.

Holland, L., A. Takacs, B. Brown, E. Gilleland, R. Hueftle, and J. Wolff, 2006: A comparison of the cloud top height product (CTOP) and cloud-top heights derived from satellite, rawinsonde, and radar. Preprints, 12th Conf. on Aviation Range and Aerospace Meteorology, Atlanta, GA, Amer. Meteor. Soc., P1.21A.

Johnston, E. C., 1995: Updated satellite technique to forecast heavy snow. Wea. Forecasting, 10, 219-228.

Kidder, S. Q., and T. H. Vonder Haar, 1995: Satellite Meteorology: An Introduction. Academic Press, 466 pp.

Landolt, S. D., R. E. Bateman, and B. C. Bernstein, 2004: A comparison of satellite and sounding derived cloud top temperatures. Preprints, 20th Conf. on Weather Analysis and Forecasting/16th Conf. on Numerical Weather Prediction, Seattle, WA, Amer. Meteor. Soc., P1.34.

Mason, B. J., and B. P. Howorth, 1952: Some characteristics of stratiform clouds over North Ireland in relation to their precipitation. Quart. J. Roy. Meteor. Soc., 78, 226-230.

Miloshevich, L. M., H. Vömel, A. Paukkunen, A. J. Heymsfield, and S. J. Oltmans, 2001: Characterization and correction of relative humidity measurements from Vaisala RS80-A radiosondes at cold temperatures. J. Atmos. Oceanic Technol., 18, $135-156$.

Mossop, S., 1985: The origin and concentration of ice crystals in clouds. Bull. Amer. Meteor. Soc., 66, 264-273.

O'Sullivan, F., C. H. Wash, M. Stewart, and C. E. Motell, 1990: Rain estimation from infrared and visible GOES satellite data. J. Appl. Meteor., 29, 209-223.

Peppler, W., 1940: Unterkühlte Wasserwolken und Eiswolken (Supercooled water clouds and ice clouds). Forschungs Erfahrungsberichte Reichswetterdienstes, B (1), 3-68.

Plank, V. G., D. Atlas, and W. H. Paulsen, 1955: The nature and detectability of clouds and precipitation as determined by 1.25-centimeter radar. J. Meteor., 12, 358-378.

Pruppacher, H. R., and J. D. Klett, 1997: Microphysics of Clouds and Precipitation. Kluwer Academic, $954 \mathrm{pp}$.

Roebber, P. J., S. L. Bruening, D. M. Schultz, and J. V. Cortinas Jr., 2003: Improving snowfall forecasting by diagnosing snow density. Wea. Forecasting, 18, 264-287.

Rogers, R. R., and M. K. Yau, 1989: A Short Course in Cloud Physics. 3rd ed. Pergammon, 293 pp.

Schmit, T. J., E. M. Prins, A. J. Schreiner, and J. J. Gurka, 2001: Introducing the GOES-M imager. Natl. Wea. Dig., 25 (3-4), 28-37.

Schultz, D. M., J. V. Cortinas Jr., and C. A. Doswell III, 2002: Comments on "An operational ingredients-based methodology for forecasting midlatitude winter season precipitation." Wea. Forecasting, 17, 160-167.

Scofield, R. A., 1987: The NESDIS operational convective precipitation technique. Mon. Wea. Rev., 115, 1773-1792.

_ rainfall from satellite imagery. NOAA Tech. Memo. NESS 86, U.S. Dept. of Commerce, Washington, DC, 47 pp.

Sherwood, S. C., J.-H. Chae, P. Minnis, and M. McGill, 2004: Underestimation of deep convective cloud tops by thermal imagery. Geophys. Res. Lett., 31, L11102, doi:10.1029/ 2004GL019699.

Vicente, G. A., R. A. Scofield, and W. P. Menzel, 1998: The operational GOES infrared rainfall estimation technique. Bull. Amer. Meteor. Soc., 79, 1883-1898.

Wang, J., and W. B. Rossow, 1995: Determination of cloud vertical structure from upper-air observations. J. Appl. Meteor., 34, 2243-2258.

Weickmann, H. K., 1957: Physics of precipitation. Meteorological Research Reviews: Summaries of Progress from 1951 to 1955, Meteor. Monogr., No. 18, Amer. Meteor. Soc., 182-225. 